\title{
Professional Football, Stadiums and Global Markets
}

\author{
Giuseppe Cappiello*
}

\begin{abstract}
The world of sport, as an economic phenomenon, is an array of extremely complex elements.

In this context, professional football clubs are amongst the best-known entities to the general public. Clubs are where the interests of media, sponsors and all others involved are concentrated most.

In conditions of over-supply and globalisation, professional football clubs must try to maximise returns on connections with fans (fan value) 'seven days out of seven', or give value to fans identifying a market-driven management of the offering presented.
\end{abstract}

Keywords: Sport Management; Professional Football; Football Club Revenues; Football Ticket Prices; Global Markets

\section{Professional Football and Global Markets}

The world of sport, as an economic phenomenon, is an array of extremely complex elements: a mix of a great many initiatives and players gravitating around a sporting event makes it difficult to set borders to an environment so rich in resources, professional commitment and human passion. In this context, professional football clubs are amongst the best-known entities to the general public. These clubs are where the interests of media, sponsors and all others involved (from clothing manufacturers to sports administrators) are concentrated most. Italian Serie A teams alone register turnovers of more than $€ 1000$ million and, as a whole, the football 'industry' is ranked 12th nationwide.

Considering professional football in managerial economic terms means, first of all, trying to identify what creates value for customers (Day, 1990; Best, 1997). That is, those offering characteristics through which a buyer can express his assessment. In essence, by 'value for customer' we mean the utility a customer

\footnotetext{
* Assistant Professor of Management, Alma Mater Studiorum-University of Bologna (giuseppe. cappiello@unibo.it)
} 
perceives for what he has received related to the economic sacrifice sustained to obtain it (Zeithaml, 1988).

This study begins from one consideration: there has been general, all round demand for innovative formulas to attract the paying public into stadiums against a pressing competition from sports entertainment available through the mass media and a fall in public safety conditions. The 'basket of attributes' product concept is just about consolidated in marketing (Lambin, 2001), whereby combinations of distinct features contribute as the sum of many to the value of the offering as a whole. The sports product is not an exception to this - so the market offering for a football event ticket has a main element, the match, and a series of peripherals attracting a greater willingness to pay by customers/fans. Finding the value a customer attributes to an individual offering can mean strengthening the link to demand for a producer, consolidating a competitive advantage and usually obtaining a 'price premium' (customer value management).

\section{Football Club Revenues}

Football club revenue sources can be split into three macro groups: income from match tickets, image rights and commercial earnings in general (sponsorship, merchandising, licensing) and revenues from other less common activities. Each of these three income types represents a third of revenues, thus all three must be continually developed, especially as a present-day football club's balance sheet does not seem to bring in the same results as on the field (Lago-BaroncelliSzymanski, 2004).

Match earnings, or the so-called ticket office takings, are the most traditional form of revenue. We must not underestimate the degree to which a strong public attendance contributes considerably to product quality from the point of view of transmitting pictures of a football event (through television or even photos). A halfempty stadium often means that a match is not of much interest, in terms of both technical team level and championship competition status. In this sense, some studies have shown that the public is not so much interested in a balanced championship as in the perception of each person's team game quality level. At the same time, the chances for a team to achieve good results from a competitive, event standpoint also depends on the amount the club can spend and on the hiring of new players. (Szymanski, 2004).

Within the match revenue mix, a major element is plant facility design/layout and management. Over the last few years, there has been a trend to converting sportsonly structures through integration with other commercial activities and turning them into family entertainment venues (Cafferata, 1998; Siegfried-Zimbalist, 2000). 
Table 1: Use of Facilities in Europe

\begin{tabular}{|c|c|c|c|c|}
\cline { 2 - 5 } \multicolumn{1}{c|}{} & $\begin{array}{c}\text { Average } \\
\text { capacity }\end{array}$ & $\begin{array}{c}\text { Stadiums } \\
\text { Degree } \\
\text { of use }\end{array}$ & $\begin{array}{c}\text { with } \\
\text { athletics } \\
\text { track }\end{array}$ & $\begin{array}{c}\text { Averag } \\
\text { e age of } \\
\text { structure }\end{array}$ \\
\hline Italy & 52,000 & $57 \%$ & $56 \%$ & 37 \\
\hline England & 30,000 & $77 \%$ & $0 \%$ & 5 \\
\hline Spain & 41,000 & $63 \%$ & N.A. & N.A. \\
\hline
\end{tabular}

Source: McKinsey

\section{Ticket Prices}

Football clubs present a high differentiation policy. A football stadium is usually split into differently priced ticket sections: going from the so-called popular sections, with prices between $€ 15$ and $€ 20$ and up to $€ 200-300$ for really important matches for the stadium's under-cover centre seats. There are different variations between these two extremes based on stadium features and the intention to capture various spectator types. At the Milan 'Meazza' stadium, F.C. Internazionale and A.C. Milan usually divide the stands into 11 macro-sections which, in turn, can be split into 136 micro-sections. One of the biggest problems club stadium managers face comes up with seating plans of this kind: how to make the difference in prices for the various sections as gradual as possible and avoid favouring ticket touts.

Over recent years, offering differences have gone beyond the traditional adult/child split (full/reduced ticket prices). Here there are other forms of personalisation and still more types being created, especially for subscriptions linked to special campaigns to attract some interesting categories: special prices for women, for the elderly and the very young are amongst those forms to be applied with the most success. To substantiate this new trend, the current S.S. Lazio 2003/04 season ticket campaign is proof. It offers women and children special grandstand seating at $€ 90$ instead of $€ 200$, and the package woman + child for the Monte Mario stand at just $€ 360$.

Another aspect requiring a different price level is match importance: opposing team value allows price leverage and can generate a price increase. As evidence of this, Table 2 below shows the strategy adopted by A.C. Milan when setting ticket prices for championship matches based on opposing team importance: 
Table 2: Ticket Prices for Championship Home Matches

\begin{tabular}{|l|c|c|}
\hline \multicolumn{1}{|c|}{ SECTION } & $\begin{array}{c}\text { STANDARD } \\
\text { MATCH in } €\end{array}$ & $\begin{array}{c}\text { MATCHES } \\
\text { AGAINST INTER } \\
\text { AND JUVENTUS in } €\end{array}$ \\
\hline West Honour stand & 270.00 & 270.00 \\
\hline West seats & 150.00 & 160.00 \\
\hline East honour stand & 82.00 & 99.00 \\
\hline $1^{\text {st }}$ east ring & 66.00 & 82.00 \\
\hline $1^{\text {st }}$ north/south ring & 31.00 & 39.00 \\
\hline $2^{\text {nd }}$ west/east ring & 31.00 & 39.00 \\
\hline $2^{\text {nd }}$ north/south ring & 15.00 & 20.00 \\
\hline $3^{\text {rd }}$ south/west ring & 11.00 & 13.00 \\
\hline
\end{tabular}

Source: http://www.acmilan.com

Another way to apply a price discrimination policy is through the number of stadium entries that can be purchased. In this case, the option normally adopted is a season's ticket to all regular season home matches paid for in advance. This has a double benefit: for fans it ensures a seat with no extra sacrifice and considerable savings (at Internazionale it means having seventeen matches available but only paying for ten), and for clubs it means up-front cash flow.

In addition to this option, some clubs have tried midway options such as a monthly subscription or for a reduced number of matches. These proposals are normally called mini-subscriptions ${ }^{1}$. Whatever version is chosen, there is up-front cash flow and committed attendance. This has lead to the use of personalised subscriptions as gifts for Christmas or for other occasions. In the strategy behind certain offerings, it could be worthwhile placing emphasis on the attraction of individual matches. One of the main problems a club has is the massive flow of spectators during a big match compared to reduced attendances for second level matches. An objective could be to link big and small events through offerings including matches with different level teams. This would not just give a club immediate ticket sales for more important matches but would also offer it the chance to increase public attendance for less interesting matches.

Finally, as a stadium has a limited number of seats, demand must be matched with availability. Empty seats in a stadium are a revenue loss that cannot be recovered. There seems to be a pretty high number of seats not sold if we consider that the utilization percentage for professional football stadiums is an average $63.3 \%^{2}$.

\section{A Study of Ticket Prices}

In order to check whether revenues can be increased through selling tickets with additional services (i.e. home delivered) or linked directly to other events (a basketball game) we did an empirical survey by interviewing 400 people during a 2003/2004 Serie A Championship match.

We used a multi-varied analysis statistical technical note method - Conjoint Analysis - allowing to measure attributes of a product/service to purchaser 
preference as a whole. Conjoint Analysis is usually applied to answer questions such as: what product/service features are important or not for the consumer? What attribute levels are desirable to a greater or lesser extent in consumer decisions? What individual target should be aimed at?

Each person interviewed was asked to express a preference out of a series of questionnaire, called 'profiles'. We then analysed 367 questionnaires, as 33 were incomplete. The sample analysed was $74.4 \%$ men and $60 \%$ of those interviewed live in Bologna or the surrounding province. Students represented $24.3 \%$ of the total, $30 \%$ were white-collar workers, $15.3 \%$ blue collar and $10.4 \%$ freelance professionals. The questionnaire was given to spectators in different parts of the stadium: curve, sides, centre stand and covered centre stand.

The survey aimed to measure preferences associated with specific factors influencing buying a ticket for a football match: stadium seat, the chance to get a $50 \%$ discount on basketball game tickets, seeing a match against one of the leading five teams, ticket home delivery and ticket price. In particular, people were asked not to just consider individual factors but an 'offer package' (profiles) that differed in at least one of the modes associated with the variables considered. Application of Conjoint Analysis then allowed us to break up overall results into partial uses associated with each mode for the factors studied. The approach used to present the profile is full-profile: each interviewee had to assess, through a 7 point Likert scale (like/do not like), profiles containing all the variables.

By applying the SPSS Categories model, the orthogonal profiles submitted to interviewees were constructed automatically. This procedure supplied 16 stimuli to which two holdouts were then added aimed at analysing predictive model validity. This technique gave us disaggregated results for individual interviewees and aggregated results for the sample as a whole. As far as the sample as a whole is concerned, we could see that 'price' and 'stadium seat' factors - the part of the stadium from which the match is watched - are the elements that most influence interviewee preference. Respectively 31.75 and 31.10 associate more preference to it. Following this, high importance is given to being able to watch a match against one of the leading five teams (16.72) and then less importance to the others: 10.75 for a $50 \%$ discount on basketball game tickets and 9.68 for ticket home delivery.

The greater the importance given to a certain factor, the greater the discriminating power of the levels associated with it. Partial utility analysis shows to what degree and in which direction different modes change preference make-up. For the 'stadium seat' factor, what most attract customers are 'centre stand' $(0.3668)$ and 'covered centre stand' (0.3157), while 'curve' (-0.4050) and 'side' (-0.2776) influence preference negatively. The 'price' factors change preferences linearly, so much so that the less customers perceive a utility, the more the level considered is penalised. In other words, the higher the price, the less the utility perceived: 0.7230 (€ 30), -1.6869 (€ 70) and -2.6509 (€110).

The Pearson and Kendall indexes, calculated on observed and estimated values for the 16 profiles assessed by the interviewee, allow us to say that the estimated model adapts to interviewee preference well. Indeed, the two indexes take on a close to unit value. This shows that the starting hypotheses, both those regarding variables to be included in the model and those on how it should be set out and on relation between preference expressed and factor levels, were formulated correctly. 
An important consideration emerges from the above: football match spectators give most importance to what seat they have and how much it costs. What influences preference most is the presence or not of one of these two factors. Importance given to them is decidedly higher than the importance given to the other three factors considered. Amongst the latter group is the chance to watch a more interesting match or, better, a match with a team from one of the championship top five.

Using the Conjoint Analysis results, we simulated profiles to highlight potential customer choice profiles. We particularly tried to test willingness to pay a higher price in exchange for the chance to use the additional services in the survey. $54.53 \%$ of our sample would choose to pay an extra $€ 20$ to be able to watch a match against one of the leading five teams (Table 3 ).

Table 3: Simulation

\begin{tabular}{|c|c|c|c|c|c|c|c|}
\hline Card & Seat & Discount & Match & Delivery & Price & TKT & Logit \\
\hline $\mathbf{1 9}$ & Curve & No & No & No & $€ 70$ & $45.47 \%$ & $41.40 \%$ \\
\hline $\mathbf{2 0}$ & Curve & No & Yes & No & $€ 90$ & 54.53 & 58.60 \\
\hline
\end{tabular}

The willingness to pay a higher price goes up to $€ 40$ if in addition to watching a match against one of the leading 5 championship teams a $50 \%$ discount on basketball game tickets is offered (Table 4).

Table 4: Simulation

\begin{tabular}{|c|c|c|c|c|c|c|c|}
\hline Card & Seat & Discount & Match & Delivery & Price & TKT & Logit \\
\hline $\mathbf{1 9}$ & Curve & No & No & No & $€ 70$ & $45.73 \%$ & $41.94 \%$ \\
\hline $\mathbf{2 0}$ & Curve & Yes & Yes & No & $€ 110$ & 54.27 & 58.06 \\
\hline
\end{tabular}

$52.37 \%$ of those interviewed were willing to pay an extra $€ 50$ if the choice of 'side' seat at the stadium was included (Table 5).

Table 5: Simulation

\begin{tabular}{|c|c|c|c|c|c|c|c|}
\hline Card & Seat & Discount & Match & Delivery & Price & TKT & Logit \\
\hline $\mathbf{1 9}$ & Curve & No & No & No & $€ 70$ & $47.63 \%$ & $44.68 \%$ \\
\hline $\mathbf{2 0}$ & Side & Yes & Yes & No & $€ 120$ & 52.37 & 55.32 \\
\hline
\end{tabular}

To sum up, it is obvious that fans give greater importance to the place they watch a match from inside the stadium and that the willingness to pay a higher price increases as the number of complementary services included in the price increase even though interest in the latter is still somewhat residual. We seem to have a buyer who is still very interested in the sport and competition factor of a football match and not just a simple spectator looking for entertainment as some would want to describe him or her. 


\section{Conclusions}

Revenues from spectators who come into a stadium to watch a football match, as described above, is a considerable share of the total revenues for a professional football club. The aim of this work was to investigate the problem of increasing revenues in a traditional way, that is, creating new services and discriminating prices based on a new offering and where facilities are designed for this use mainly on Sundays.

Results do not lead to generalisations for a number of reasons but do at least provide an indication that the growing sports event offering leads to considering the 'one out of seven' solution by now obsolete, as the chance to increase revenues through direct participation at sports events is somewhat limited.

Under conditions of oversupply and globalisation in the distribution of sporting images, professional football clubs must try to maximise returns on connections with fans (fan value) 'seven days out of seven', or give value to fans identifying with their team or favourite athlete through modern communication strategies and a more market-driven conception of the offering presented.

\section{Bibliography}

Best Roger J., Market Based Management, Prentice Hall, Upper Saddle River, 1997.

Cafferata Roberto, Tendenze strutturali della crescita dello sport come 'business', Economia $e$ Diritto del Terziario, n. 1, 1998.

Day George S., Market-Driven Strategy, Free Press, New York, 1990.

Lago Umberto, Baroncelli Alessandro, Szymanski Stefan, Il business del calcio: successi sportivi e rovesci finanziari, Egea, Milan, 2004.

Lambin Jean-Jacques, Marketing strategico e operativo, Mc Graw Hill, Milano, 2001.

Mauri Aurelio, La gestione delle società di calcio: il portafoglio attività, Economia e Diritto del Terziario, n. 3, 1999.

Siegfried John, Zimbalist Andrew, The Economics of Sports Facilities and Their Communities, Journal of Economic Perspectives, Summer, 2000. http://dx.doi.org/10.1257/jep.14.3.95

Zeithaml Valarie A., Consumer Perception of Price, Quality, and Value: a Means-End Model and Synthesys of Evidence, Journal of Marketing, July, 1988.

http://dx.doi.org/10.2307/1251446

\section{Notes}

${ }^{1}$ Over recent years, there has been a growing spread of these kinds of subscription, especially for the eliminating stages of the Champions League.

${ }^{2}$ Source: Football League survey 